\title{
SERUM HOMOCYSTEINE LEVELS IN CEREBROVASCULAR ACCIDENTS
}

\author{
Zolianthanga Zongte, L Shaini, Asis Debbarma, Th Bhimo Singh*, S Bilasini Devi and WG Singh \\ Departments of Biochemistry and *Medicine, Regional Institute of Medical Sciences, Imphal
}

\begin{abstract}
Hyperhomocysteinemia has been considered an independent risk factor in the development of stroke. The present study was undertaken to evaluate serum homocysteine levels in patients with cerebrovascular accidents among the Manipuri population and to compare with the normal cases. Ninety-three cerebrovascular accident cases admitted in the hospital were enrolled for the study and twenty-seven age and sex matched individuals free from cerebrovascular diseases were taken as control group. Serum homocysteine levels were estimated by ELISA method using Axis homocysteine EIA kit manufactured by Ranbaxy Diagnostic Ltd. India. The finding suggests that hyperhomocysteinemia is associated with cerebrovascular accident with male preponderance, which increases with advancing age. However, whether hyperhomocysteinemia is the cause or the result of cerebrovascular accidents needs further investigations.
\end{abstract}

\section{KEY WORDS}

Hyperhomocysteinemia, Cerebrovascular accident, Homocysteine.

\section{INTRODUCTION}

Homocysteine (Hcy) is sulfur containing amino acid and an intermediate in methionine metabolism. Hcy when produced in excess is excreted out of the tightly regulated cell environment into the blood. In many individuals with inborn errors of Hcy metabolism, kidney or liver disease, nutrient deficiencies, or concomitant ingestion of certain pharmaceuticals, Hcy levels can rise beyond normal levels and can lead to adverse health outcomes (1). In a study involving over 4000 subjects it was reported that Hcy was an independent risk factor for cardiovascular disease (CVD) and estimated that $10 \%$ of the CVD risk is attributable to elevated Hcy (2). Vascular disease of the brain, inspite of recent and gratifying reduction in its incidence, remains a very important cause of neurologic morbidity and mortality. Cerebrovascular disease occurs predominantly in the middle and late years of life. They cause approximately 2,00,000 deaths as well as neurologic disability in the United States each year. In the

\section{Address for Correspondence :}

Prof. W. Gyaneshwar Singh

Department of Biochemistry

Regional Institute of Medical Sciences,

Imphal, Manipur - 795004

E-mail : wg_singh@yahoo.co.in
United States, it is the third leading cause of death. Stroke and other cerebrovascular disease killed about 4 million people in 1993 , representing $7.5 \%$ of total global deaths from all causes (3). Hyperhomocysteinemia has been emerging as an independent risk factor for atherosclerosis. Several workers opined that moderately elevated plasma Hcy concentration might be an independent risk factor for cerebrovascular disease including stroke and transient ischaemic attack (4, 5). In Regional Institute of Medical Sciences Hospital Imphal, a minimum of 84 deaths was reported each year due to cerebrovascular accidents. As per the available hospital records, there were about 2026 cases of cerebrovascular accidents, and out of which 549 died between the years 1997 to 2002, with an increasing trend each year. The levels of serum homocysteine were not looked into in such cases in the context of Manipuri populations. Manipur is a small state situated in the northeast corner of India; the natives of which are distinct ethnically, socially and culturally from those of the rest of the country. The Manipuris belong to the Tibeto Mongoloid group with a dietary habit different from that of the other Indians, the staple food being rice and fish.

The present study is therefore undertaken to estimate the serum total Hcy levels in normal subjects and in cerebrovascular accident cases with the aim to search for the association of homocysteine and cerebrovascular accidents among Manipuris. 


\section{MATERIALS AND METHODS}

Study Population : Ninety-three patients presenting with cerebrovascular accidents consisting of both hemorrhagic and infarction admitted in the Medicine Ward at Regional Institute of Medical Sciences hospital over a period of one year were enrolled in the study. A detailed medical history was obtained and all patients were subjected to standard investigations including neurological examinations, brain CT scan and all routine investigations like routine blood examinations liver function test, kidney function tests, urine examination, chest X-ray, ECG, EEG etc. Other related examinations were performed when indicated. Evaluation of previous cerebrovascular events and events that occurred during the study was performed according to the World Health Organization definitions of stroke or TIA (6). Twenty seven age and sex matched subjects who do not have a history or signs of cerebrovascular diseases were recruited to form the control group. Brain imaging was not performed in the controls. All patients and controls were received by one physician and were subjected to a standardized clinical assessment. For control group, individuals who are smokers, alcoholics, diabetics and hypertensive or with renal diseases were excluded from the study as such conditions are reported to have increased serum homocysteine levels (1). Informed consent was obtained from all participants and the Institute ethics committee approved the study protocol.

Blood sampling and laboratory methods : In all the patients, for estimation of homocysteine, blood sample was taken at least 2 months after the last clinical event because both depression of homocysteine levels and transient elevations of some endothelial markers have been reported in the first few weeks after acute stroke (7). Two milliliters of blood was collected in polypropylene tubes. Specimens were centrifuged at $3000 \mathrm{rpm}$ for 10 minutes to obtain serum. The isolated sera were stored at $-20^{\circ} \mathrm{C}$ until use. All the chemicals and reagents used in the study were of analytical grade. Serum total homocysteine concentration was measured using Enzyme Linked. Immunosorbant Assay as described by Frantzen et al using Axis-homocysteine EIA Kit form Ranbaxy Diagnostic Ltd. India (8).

Out of another $10 \mathrm{ml}$ of fasting sample collected, $2 \mathrm{ml}$ was placed in fluoride vials for estimation of random blood sugar and rest of the sample was collected in polypropylene tubes to obtain serum for estimation of serum triglyceride (TG), total cholesterol, high density lipoprotein (HDL) and serum creatinine concentrations.
Random blood glucose was determined by GOD-PAP method using glucose liquicolor kit manufactured by Human, Germany (9). Total cholesterol was estimated by the enzymatic method of Allain et al with kits obtained from Ranbaxy Diagnostic Ltd., India (10). Quantitative estimation of serum triglyceride was done by the method of Bucole and Harold (11). HDL Cholesterol was determined by precipitation technique of Steele et al using kits from Ranbaxy Diagnostics Ltd., India (12), serum creatinine was estimated by Jaffe Reactions using photo colorimetric tests (13).

Statistical methods used: All the results were expressed as Mean \pm SD. Fisher's 't' test was applied to assess the statistical significance of the results. $P$ values $<0.05$ were considered significant. The statistical analysis was carried out using SPSS version 11.5-computer soft ware.

\section{RESULTS}

Cerebrovascular accident patients and controls were well matched for age and gender (Table1). Cerebrovascular accident seems to have a male preponderance over female having a ratio of $64: 29$. The mean homocysteine level is also

Table 1: Sex wise distribution and Mean Age \pm SD in cases and controls

\begin{tabular}{lllll}
\hline Study Group & Gender & $\begin{array}{c}\text { Mean } \\
\text { Age }\end{array}$ & SD & $P$ \\
\hline Cases & Male $(n=64)$ & 62.19 & 13.12 & \\
$(n=93)$ & Female $(n=29)$ & & & 0.113 \\
Control & Male $(n=16)$ & 57.85 & 9.65 & \\
$(n=27)$ & Female $(n=11)$ & & & \\
\hline
\end{tabular}

$\mathrm{P}>0.05$ (Insignificant)

higher in males than in females showing $15.67 \pm 67 \mathrm{mmol} / \mathrm{L}$ and $14.62 \pm 5.70 \mathrm{mmol} / \mathrm{L}$ respectively as seen in Table2. The maximum number of cases are in the age group $65-75$ years with homocysteine levels of $16.22 \pm 6.00 \mathrm{mmol} / \mathrm{L}$. The highest Hcy level was observed in the age group 74 years and above. This implies that the level of homocysteine increases as age

Table 2 : Sexwise distribution of levels of Homocysteine in study group

\begin{tabular}{lccc}
\hline Sex & No. of cases & $\begin{array}{c}\text { Homocysteine } \\
\text { Mean } \pm \text { SD }(\mu \mathrm{mol} / \mathrm{L})\end{array}$ & $\mathrm{P}$ \\
\hline Male & 64 & $15.64 \pm 6.70$ & 0.47 \\
Female & 29 & $14.62 \pm 5.70$ & \\
\hline
\end{tabular}

$P>0.05$ (Non Significant) 
Table 3 : Age wise distribution of Homocysteine level in study group

\begin{tabular}{lccccc}
\hline \multirow{2}{*}{ Age $(\mathrm{yrs})$} & \multicolumn{2}{c}{ Control } & & \multicolumn{2}{c}{ Study } \\
\cline { 2 - 3 } \cline { 5 - 6 } & No. of cases & $\begin{array}{c}\text { Homocysteine } \\
(\mu \mathrm{mol} / \mathrm{L})\end{array}$ & & $\begin{array}{c}\text { No. of } \\
\text { cases }\end{array}$ & $\begin{array}{c}\text { Homocysteine } \\
\mu \mathrm{mol} / \mathrm{L}\end{array}$ \\
\hline $25-34$ & 1 & $11.00 \pm 0.00$ & 2 & $12.00 \pm 1.42$ \\
$35-44$ & 2 & $10.00 \pm 3.41$ & 7 & $12.43 \pm 3.41$ \\
$45-54$ & 6 & $13.00 \pm 4.00$ & 12 & $13.07 \pm 4.04$ \\
$55-64$ & 10 & $12.70 \pm 3.37$ & 27 & $15.38 \pm 6.99$ \\
$65-74$ & 7 & $12.14 \pm 2.2$ & 29 & $16.22 \pm 6.00$ \\
75 \& above & 1 & $13.00 \pm 0.00$ & 16 & $16.56 \pm 7.75$ \\
\hline
\end{tabular}

Comparison was done between age groups : P > 0.05 (Non Significant)

advances (Table 3). When the levels of total Hcy is compared between the cases and control, the study group has $15.32 \pm$ $6.39 \mathrm{mmol} / \mathrm{L}$ whereas in the control, it is $12.51 \pm 3.34 \mathrm{mmol} / \mathrm{L}$ which is statistically significant $(P<0.05)$ (Table 4). Again from Table 5, we observed that blood sugar levels are higher in cases $(115.59 \pm 42.8 \mathrm{mg} / \mathrm{dl})$ than control $(83.37 \pm 14.28 \mathrm{mg} /$ dl) which is significant $(P<0.05)$. HDL cholesterol level is significantly low in study group when compared with control group $(P<0.05)$. Total cholesterol level is significantly higher in patients $(185.47 \pm 42.3 \mathrm{mg} / \mathrm{dl})$ than in controls $(160.5 \pm$ $26.12 \mathrm{mg} / \mathrm{dl}$ ) whereas no significant difference could be observed in serum trglycerides and creatinine levels.

Table 4 : Homocysteine levels in cases and controls

\begin{tabular}{lccccc}
\hline Study group & No. of cases & $\begin{array}{c}\text { Range } \\
(\mu \mathrm{mol} / \mathrm{L})\end{array}$ & $\begin{array}{c}\text { Mean } \\
(\mu \mathrm{mol} / \mathrm{L})\end{array}$ & SD & $\mathrm{P}$ \\
\hline Case & 93 & $5-38$ & 15.33 & 6.39 & \\
Control & 27 & $6-20$ & 12.52 & 3.34 & 0.030 \\
\hline
\end{tabular}

$\mathrm{P}<0.05$ (Significant)

\section{DISCUSSION}

Increasing age and male sex is associated with higher total Hcy concentrations (14). The difference between the sexes could be due to large muscle mass in men since the formation of muscle is associated with the simultaneous formation of
Hcy in connection with creatine/creatinine synthesis (15). The increase in plasma Hcy may also be due to the influence of sex hormones (16). The concentrations of total Hcy was significantly higher in study group than in controls. Further, patients with cerebrovasular accident had elevated levels of blood sugar and serum cholesterol with low HDL-cholesterol. These observations are consistent with that of Tanne et al (17). Kam et al (18) also found a strong association between plasma total Hcy and atherothrombotic disease, which is consistent with our findings. Epidemiological studies have demonstrated that hyperhomocysteinemia is an independent risk factor for stroke (19). However, the molecular mechanism by which Hcy promotes atherothrombosis is unknown. Experimental evidence suggests that atherogenic propensity associated with hyperhomocysteinemia results from endothelial dysfunction. Endothelial cell injury, platelet activation, deleterious effect on thrombomodulin expression, protein $\mathrm{C}$ activation, and an increased oxidizability of LDL have been described as a few possible mechanism by which homocysteine provokes arteriosclerosis and thrombosis (20).

From this study, it is observed that total Hcy level is significantly higher in patients with stroke (cerebral infarction) than healthy controls. Now a days, hyperhomocysteinemia is considered an independent risk factor for the incidence of stroke, even though there is lack of convincing explanation till date. This study though of small size, suggests that hyperhomocysteinemia occurs in patients of cerebrovascular accident among Manipuris. However, the association of homocysteine and stroke need to be investigated Manipuris.

\section{REFERENCES}

1. Thomas G Guilliams. Homocysteine - A Risk Factor for Vascular Diseases: Guidelines for the Clinical Practice. J Am Nutraceutical Assoc Winter 2004; 7:11-14.

2. Boushey CJ, Beresford SA, Omenn GS, Motulsky AG. A quantitative assessment of plasma homocysteine as a risk factor for vascular disease: probable benefits of increasing folic acid intakes. JAMA1995; 274: 1049-57.

Table 5 : Blood sugar, serum creatinine, total cholesterol, and triglyceride and HDL level in study and control group

\begin{tabular}{lccccc}
\hline & Blood Sugar $(\mathrm{R})(\mathrm{mg} / \mathrm{dl})$ & Creatinine $(\mathrm{mg} / \mathrm{dl})$ & HDL $(\mathrm{mg} / \mathrm{dl})$ & Total Chol $(\mathrm{mg} / \mathrm{dl})$ & Triglycerides $(\mathrm{mg} / \mathrm{dl})$ \\
\hline Cases $(\mathrm{n}=93)$ & $115.59 \pm 42.80^{*}$ & $1.17 \pm 1.27$ & $42.66 \pm 10.31^{*}$ & $185.48 \pm 43.33^{*}$ & $122.28 \pm 80.75$ \\
Control $(\mathrm{n}=27)$ & $83.37 \pm 14.28$ & $1.07 \pm 1.20$ & $48.19 \pm 8.74$ & $160.54 \pm 26.13$ & $98.63 \pm 30.61$ \\
\hline
\end{tabular}

${ }^{*} \mathrm{P}<0.05$ (significant) 
3. Smith WS, Stephen L, Hauser J, Donald Easton. Cerebrovascular Diseases. In: Harrison's Principles of Internal Medicine, 15th Edition, New York, USA 2001: Vol. 2: 2369-91.

4. Bruce MC, Rene MN, Breamer MS, Gary S, Frank N, Pat deGarmo. Elevated plasma homocysteine concentrations as a possible independent risk factor for stroke. Stroke 1990; 21: $527-76$.

5. Brattstrom $L$, Israelsson $B$, Norrving $B$, Bergqvist $D$, Thorne J, Hultberg B, Hamfelt A. Impaired homocysteine metabolism in early - onset cerebral and peripheral occlusive arterial disease. Effect of pyridoxine and folic acid treatment. Atherosclerosis 1990; 81: 31-60.

6. Report of the WHO task force on stroke and other cerebrovascular disorders. Stroke: Recommendations on stroke prevention, diagnosis and therapy. Stroke 1989; 20 : 1407-31.

7. Linsberg PJ, Carpen O, Paetau A, Karjalainen, Linsberg ML, Kaste M. Endothelial ICAM-1 expression associated with inflammatory cell response in human ischaemic stroke. Circulation 1996; 94: 939-45.

8. Frantzen F, Faaren AL, Alfheim I, Nordhei AK. An enzyme conversion immunoassay for determining total homocysteine in plasma or serum. Clin Chem 1998; 44: 311-6.

9. David B, Sacks. Carbohydrates. In: Teitz's Fundamentals of Clinical Biochemistry. Editors Carl A Burtis and Edward R Ashwood. 5th Ed., Philadelphia, W.B. Saunders Company, 2001: 427-61.

10. Allain CC, Lucy SP, Chan CG, Richard W, Paul CF. Enzymatic determination of total serum cholesterol. Clin Chem 1974; 20: $470-81$.

11. Bucole G, Harold D. Quantitative determination of serum triglyceride by the use of enzymes. Clin Chem 1973; 19: 476-81.

12. Steele BW, Kocher DF, Azar MM, Blas Z, Kpwaski PT. High densities lipoprotein fractions, prepared by precipitation technique. Clin Chem 1976; 22: 98-101.
13. David J, Newman C, Price P. Non protein nitrogen metabolites. In Tietz Fundamentals of Clinical Chemistry 5th Edn. Editors. Carl, A., Burtes and Edward R. Ashwood. Philadelphia; W.B. Saunders Company, 2001: 414-26.

14. Anderson $A$, Brattstrom $L$, Israelson $B$, Isaksson $A$, Hamfelt A, Hultberg B. Plasma homocysteine before and after methionine loading with regard to age, gender and menopausal status. Eur J Clin Investig 1992; 22: 79-87.

15. Norlund L, Grebb A, Fex G, Leksell H, Nilsson JE, Schenk $\mathrm{H}$, Hultberg $\mathrm{B}$. The increase of plasma homocysteine concentrations with age is partly due to deterioration of renal function as determined by plasma cystatin C. Clin Chem Lab Med 1998; 36: 175-8.

16. Arlene L, Arabi N, Kristopher A, Women D, Kruger Tarig Abou - Ghazala, Fadi A, Maher N, Anjan G, Ali M et al. Reduction of homocysteine levels in coronary artery disease by low dose folic acid combined with vitamins $B_{6}$ and $B_{12}$. Am J Cardiol 1999; 83: 821-5.

17. Tanne D, Haim M, Goldbourt U, Boyko V B, Doolman R, Adler Y, Brunner D, Behar S, Sela BA. Prospective study of patients with homocysteine and risk of ischaemic stroke among patients with pre-existing coronary heart disease. Stroke 2003; 34: 632-6.

18. Kam SW, Mu Qiao Ping C, Peter YK, Poon Anna KY, Chan Josheph TF, Lau Kwok P et al. Homocysteine Endothelial dysfunction and coronary artery disease: Emerging strategy for secondary prevention. J Card Surg 2002; 17: 432-5.

19. Eikelboom JW, Hankey GJ, Anand SS, Lofthause E, Staples $\mathrm{N}$, Baker RI. Association between high homocysteine and ischaemic stroke due to large and small artery disease but not other etiological subtypes of ischaemic stroke. Stroke 2000; 31: 1069-75.

20. Rodgers GM, Conn MT. Homocysteine, an atherogenic stimulus, reduces protein $\mathrm{C}$ activation by arterial and venous endothelial cells. Blood 1990; 75: 895-901. 